\title{
ON THE ECONOMIC INTERPRETATION OF PROBABILITY THEORY
}

\author{
Péter Medvegyev
}

Probability theory and the economic interpretation of probability is a perennial topic that has been explored in this journal several times already. In full concurrence with János Száz's opinion set out elsewhere in this volume ${ }^{2}$, it makes sense to start out from the premise that the complexity of the problem largely arises from the fact that we are trying to explain several unrelated questions at the same time.

JEL codes: A12, B16, Co, G17

Keywords: probability, ability of forecast, differentiability, economic interpretation of probability

Firstly, it is worth singling out the pricing of derivatives because, despite this being the flagship economic application of stochastic analysis, the theory actually has nothing to do with randomness. Or rather, it only formally appears to be associated with a type of randomness. The central idea in the pricing of derivative products is hedging. The price of a derivative is the cost of the self-financing portfolio hedging the product. If there is no hedging portfolio, which is usually the case, then the theory is unable to answer the question. What remains is the good old theory of supply and demand. This cannot be emphasised enough. There is nothing complicated about it. The prices are determined by supply and demand. In a very special situation that perhaps might never even occur in real life, where derivatives can be hedged, demand and supply are independent of preferences, in which case the price can simply be determined. The question, therefore, is whether there is a self-financing hedging portfolio. To put it another way: Are we able to solve a system of linear equations in a certain, extremely complicated mathematical situation, or not? In this sense, the question has far more to do with linear algebra or linear programming, but the story is told in an infinitely dimensional

1 Péter Medvegyev, Professor, Corvinus University Budapest. E-mail: medvegyev@uni-corvinus.hu.

2 SzÁz, JÁnos (2020): Keynes and the interpretation of probability versus the use of probability theory in option pricing. Economy and Finance 7(2), 144-155. 
space rather than a space with finite dimensions. In other words, the mathematical cloak enshrouding the content is very imposing, but it is still just a cloak. The pricing of derivative products is a chapter of the good old general equilibrium theory, and the prices are dual variables associated with the production set. The difficulty stems from the fact that the space in which the system of equations needs to be solved has infinite dimensions. Furthermore, its structure is far from simple because not only the number of individual outcomes, but also the number of individual instances is infinite. In other words, you could say that the problem is multiply infinite. If we dispense with the two infinites, the problem reveals its true nature and it turns out that the price can be derived from the duality theorem of linear programming. If the time horizon is finite, but the number of outcomes is infinite, then the discussion is still greatly simplified in comparison to the general case and it becomes clear that the separation theorem of convex sets must be applied. On the other hand, of course, treating both the time horizon and the outcomes as infinite unleashes a torrent of mathematical problems that can only be managed by the most well-prepared. The situation is further complicated by the fact that, essentially, in the simplest case where the stock prices develop according to a geometric Wiener process, a simplified path is offered by the 'Girsanov theorem'. Of course, the Girsanov theorem is not in itself a particularly simple one either, but it is still far simpler than the toolkit applied in the general case. Moreover, the change of measure described by the Girsanov theorem gives the impression that the outcomes must be assessed with some kind of subjective probability, and the derivative products can be priced as and expected value in a risk-free world. Meanwhile, the new probabilities are simply dual variables, or the shadow prices of linear programming if you prefer.

Setting aside the matter of pricing derivative products, the question is quite simple: Is the world knowable? Although pertinent, there is one big problem with this question. Neither of the two concepts that it features, 'knowable' and 'the world' are defined, so we cannot give an answer. The question is especially critical in economics because the boundaries between what constitutes a social issue, a political issue or an economic issue are extremely arbitrary. Economics debates and arguments, for the most part, revolve around the demarcation of the field. What belongs within it, and what does not. The 'what is economics' debate is always current and always fierce. And what lies behind this debate is the fact that even defining the subject is a highly arbitrary matter. The question of probability is, for the main part, associated with the question of knowability. If we know the probability of the future outcomes of each possibility, then we have learned something even if it is only the probabilities and the possible outcomes. Naturally, the main problem is that we must first draw the boundaries, describe the great mystical Omega set if you will. Given the uncertainty of economics when it comes 
to marking out boundaries, it is hardly surprising that it is even more uncertain about the assignment of probabilities. And from this point on, we can safely say that the question becomes unfathomable and, you might say, chaotic. It cannot be stressed enough that the ability to forecast economic trends depends largely on how we can localise the problem. Forecasting can be solved in an easily described system where there is a small number of well-defined variables. Referring to the question encapsulated in the title, in a badly defined system it is difficult to ensure the basic requirements of probability theory; namely, a large independent sample with equal distribution. Put another way, formally, the issue manifests itself as an inability to apply probability theory. Nevertheless, the problem lies not with the probability calculus or the frequentist interpretation of the statistics, but rather it stems from the nature of the studied phenomenon. And of course, this means that precise forecasts cannot be given using other methods either. It is perhaps worth mentioning that one of, if not the most imposing theories of physics is electromagnetic theory. To get a sense of how impressive this theory and the accumulated knowledge is, just look at your telephone. At the same time, there is still no satisfactory and convincing theory to answer the question of why and how lightning is created. ${ }^{3}$

Naturally, the scientific community is trying to improve this situation, and constructing models; in other words, it artificially designates certain questions and starts to examine them, identifying the study of the model's properties with that of the thing being modelled. Moreover, like all human activity this is also a social phenomenon; it is about influence, power and money, and the thing - the model - starts to take on a life of its own. The perpetual struggle for funds, influence and titles marshals the researchers into teams, and these teams and communities of researchers are held together at least as much by common interests as by the knowability of what they are researching. Obviously, totally absurd models cannot be promoted ad-infinitum, although he who seeks shall find, however strong the group interest may be. The interests of another team dictate that it should

3 Feynman et al. (1986): The Feynman Lectures on Physics, Volume II, Chapter 9-6, published in Hungarian as: Mai Fizika, 5. kötet, Budapest: Müszaki Könyvkiadó, 133. The cited literature is not the latest on this subject, and I do not claim to be an expert in this field, so it is possible that the matter has since been reassuringly clarified. Nevertheless, it is worth making that while under controlled conditions researchers in the field have unparalleled knowledge both mathematically and in engineering terms, when the phenomenon occurs in the wild in its own natural state it is no longer so clear what needs to be done and why things are the way they are. The problems of economics stem from the fact that there are no controlled conditions; owing to the nature of the thing, it is not reasonably possible to remove an entity from its social environment or isolate some phenomenon from its surroundings. As a student, I joked that we had to answer every question with: 'social relationship'. For example, what is price, what is demand, etc. Today I think that this was actually a wise, if not particularly ground-breaking observation. 
replace those grouped around the weaker model. And it does everything it can to achieve this. In other words, in academic life as in every area of society, the battle for resources nudges the system towards greater efficiency. The speed with which this process runs its course is another matter. Generally, the individual competing teams are in the same age group; in other words, the speed of progress is not too high, and of course there is no guarantee that the younger generation will move forwards and not backwards.

It is worth considering a somewhat abstract example of the relationship between the model and reality. The advantage of this example is that it is highly specific and well-defined. The question is as follows: How can we simulate a Poisson process with a computer? The Poisson process is a very well-defined concept in mathematics. You could say it exists objectively in the world of mathematics. If we want to simulate it with a computer, however, we are faced with a fundamental issue: The two systems have a different concept of numbers. In mathematics, we understand numbers to be real numbers, and it is the axioms of real numbers that ardent professors reveal to keen audiences at the beginning of lectures on analysis. Meanwhile, in the world of computers real numbers are defined as something completely different. Obviously, the computerised concept of real numbers seeks out the best possible approach to the mathematical concept of real numbers; but it is also clear that the possibilities are highly limited. Accordingly, the concept of time is completely different in the two systems. A computerised Poisson process will be different in every respect to a true, mathematical Poisson process. When deriving the critical properties of the Poisson process the mathematical properties of the real numbers must be exploited as fully as possible. Which properties of the real, mathematical Poisson process are important, and which of its properties can be disregarded? An addition problem is that, although we may be able to simulate many properties, this comes at the cost of time and storage capacity. In other words, we can only decide on the nature of the simulation after weighing certain limitations and certain objectives against each other.

And what about the application of the Poisson process, at the checkouts of a hypermarket for example? The Poisson process has numerous applications in the theory of queuing systems. What concept of time does the everyday shopper use, and how does this relate to the mathematical axioms of real numbers? Is service time really exponential? Or does it just seem that way? Or do we just say that it is, because that is the best we can come up with? Or, perhaps we know there is no point because the system will be badly scaled whatever happens, so it is easier to give the job of designing it to the local handyman? How far is it possible, and worthwhile, to take an examination of this question? At what point do we have to admit that the mirror through which we view the world is arbitrary, false and 
distorted. Not to mention that we are not even looking at the world, but at a movie projected onto us by another mirror.

Today almost nobody encounters reality anywhere, but only sees its reflection through multiple lenses. The reflection is so compounded that we are entirely justified in suggesting that perhaps reality does not exist at all, or if it does exist it is unrecognisable to us. The question of what probability is, and what is its correct economic interpretation, is unfortunately a false problem. There is no correct interpretation, merely the one that is expedient and useful. What is expedient and what is useful? That is another good question. The answer can only be interpreted in its complex, social contexts. Often, usefulness is whether a paper can be written on something and whether it can boost the number of citations. Sometimes it may signify whether a good trading strategy can be put together. Humankind, as they say, is a tool-making animal. We make tools to facilitate survival. The big change in intellectual tool-building that has been under way since the $19^{\text {th }}$ century is that the purpose of creating our intellectual tools is becoming less, or rather not at all, to understand world created by God. Sadly, we must recognise that the age of great discoveries is over. I know, they thought the same at the end of the $19^{\text {th }}$ century, then along came the $2 \mathrm{O}^{\text {th }}$ century and everything in the world of science was turned on its head. But just because something was true once, why would it always be true? We have seen examples of this, and of the opposite too.

Essentially, the inability of economics to foretell the future is not due to one property of probabilities or another. The problem does not lie in this or that interpretation of probability theory. The main sticking point is that it is incapable of clearly defining its own subject; it cannot isolate what it is studying from what it is not studying. You could say that there are no fixed parameters, every value is a variable. The problem lies not with the skills of the researchers nor with the unsatisfactory nature of the applied methods, but with the fact that the subject under study cannot be isolated from its environment, and nor can that environment be appropriately shaped. So-called theoretical economics attempts to mimic the methodology of successful sciences, using tools that are alien to it. It clings desperately to the illusion that it is capable of providing an explanation for the development of economic trends when it cannot even say what it is measuring, what the phenomenon that it is trying to forecast is, or even what the economic trends are and whether they can be regarded as a technical or a sociological problem. It constructs a world for itself, and as a best option examines his own creation. I must emphasize that this is not a problem. Indeed, perhaps this method is the only way. As long it is done with sufficient insight, sincerity and humility. In my view, these are precisely what are lacking. Everyone has making a living somehow and pay the tuition fees for their child's top university, because this is the entry ticket to a successful life. One hand washes the other. 
Probability theory is a fine and elegant mathematical approach with numerous theoretical pitfalls, but there is nothing better. If we look very closely, we can see even at the level of the axioms that it cannot answer a fundamental question; namely, how to calculate the probability of a intersection. The way around this is to introduce conditional probability, but we do not say how to calculate it. To be more precise, the introduced definition must always be used backwards. If we know the conditional probability, then multiplying this with the probability of the condition gives us the probability of the intersection. The elementary examples aside, we will never be able to tell the conditional probability; but this is not what interests us. What we would like to know is the probability of occurrence of the various events together; in other words, the relationship of the observed phenomena with each other. Or, if you prefer, we would like to know the co-movement, the correlation between the various events, to use the word 'correlation' in its most general sense. Conditional probability is the point at which we smuggle the properties of the phenomenon to be modelled into the probability model. For example, we might say that market prices make up a Markov chain, or that yields constitute a Lévy process. This is the problematic step in every modelling exercise. From this point on, everything is mathematics. This does not of course mean that the conclusion is correct; because, as I indicated with regard to the Poisson process, it is not certain, for example, that the calculations will not make the errors more acute due to the differing concepts of time. Since the two systems are not the same, a transformation of one model may point to a side of the other that was not visible in the initial situation. In other words, the mathematics do not necessarily help with the conclusion, but may assist with the identification of errors. It is possible, and a certainty when it comes to economic processes, that this is the more important role. In the theory of derivative pricing, the most important mathematical achievement was to demonstrate, and especially to recognise, that the completeness of the market has a key role in the derivation of the pricing formula. Contrary to introductory textbooks, it is not lack of arbitration but completeness that is the decisive condition. This has been revealed by mathematical studies. This is the contribution of the scientific community. Similarly, general equilibrium theory shows that we can only talk about the balance of supply and demand in the case of convex technologies. The errors arising during practical applications also stemmed, among other things, from the fact that the various derivative products were not really hedged; how they have been? Perfect hedging exists only in fairy tales, or in mathematics if you like.

Naturally, each era viewed the world differently. Here too, an answer to a very difficult question must be found. The 18 th and 19th centuries were very optimistic. Why? They firmly believed that the world can be known and changed. It is sufficient just listen to Beethoven. A simple, transparent structure. Everything 
is visible, everything is crystal clear and beautiful. This simplicity and magnificence impresses people of every era. Unfortunately, the optimistic 19th century vanished on the battlefields of the Great War, making way for the 2oth century. In terms of mathematics, the $19^{\text {th }}$ century was largely about differentiability. The idea that a process or formula is undifferentiable did not even come up. Differentiability, however, means the ability to forecast. Since we know the past, or think we do, we know the derivative on the left. Since the formula is differentiable, we also know the derivative on the right; that is, we know what will happen in the future. Indeed, the functions are not only differentiable, but what you might call ultradifferentiable. This is because a function was usually understood as complex, differentiable function. An important feature of complex differentiable functions is that by just observing a small piece of them the whole function can be clearly stated. For simplicity's sake, we shall define a small piece as being the value on any small time-segment of our choice. In other words, if we know a short section of a function, then we can know the entire function any time, anywhere. Full determinism. A similar logic applies to differential equations. If we know the starting conditions, then we can also know the perpetual laws of the system. Of course, mathematics is always about fifty years ahead of the world. The idea of the knowable world gradually started to disintegrate. It became increasingly clear that things are not that simple after all. The counterexamples multiplied albeit for varying reasons. The biggest blow came from trigonometric series theory. It turned out that you can make a discontinuous function from simple waves. Then came the coup de grâce. In 1872 Karl Weierstrass, the father of modern analysis, constructed a function that was continuous, but not differentiable at any point. In 1821 Augustin-Louis Cauchy, the greatest mathematician of his time, even proved that a continuous function is differentiable except at some special points. It usually pointed out that Cauchy did not see, failed to notice the difference between convergence in every point and uniform convergence ${ }^{4}$. While this is true, it is more likely that the possibility of a form of movement that we cannot forecast, at least for a short period, never even occurred to him. Cauchy's error was not mathematical, but a philosophical one. He wanted to infer something that was not true. You could say that he placed his desires before reality. Weierstrass's counterexample is a turning point in the history of science. Firstly, it became clear that intuition does not provide an adequate foundation for mathematics. Mathematics must be strictly logic-based and axiomatic. Before Weierstrass, plausibility and truth were one and the same. It was not only thought that the world was knowledge, but also that the world was simple and God did not just roll the dice, but far from being malicious was

4 Whereas today we are so clever that we would rightly fail someone for this in an exam. 
actually proud of creation; and armed with the apple from the tree of knowledge, people could marvel at creation and through it the Creator himself. At this point mathematics started to tread its own path, essentially breaking away from physics and, we should add, from applications in general. The purpose of this discipline changed. Rightly or wrongly, the concept of true was replaced by the concept of logically flawless. Rightly or wrongly it only treats intuition as an important aid for supposition. However obvious something may be, that does not make it true; the statement must be derived from the axioms. This is also reflected in the external appearance of published literature on mathematics. A "good" mathematics book has no illustrative diagrams. This contrasts with all the other disciplines, including economics, where a good chart is worth more than a thousand words. Dirac was reportedly asked what the difference is between physics and mathematics. According to Dirac, both sciences are about equations; indeed, the very same equations. But a physicist, based on intuition, can tell you the solution to the equation and the approximate properties of the solution without solving it. A mathematician needs to solve the equation and analyse it to know the answer. In fact, we should add to this that a mathematician's first thought is to ascertain that there is a solution; that is, that the equation contains no internal contradictions.

Kolmogorov's probability axioms are a typical example of this endeavour. These make up a system of axioms and definitions that render the calculations correct and mathematically manageable. His principal means of achieving this is to base the concept of expected value on the abstract Lebesgue integral. In other words, the aim is for the system to be logically stable and easy to use. The tool for this is a new "interpretation" of a mathematical theory that had only just emerged. After this, he naturally went on to prove brilliant mathematical theorems, such as the strong law of large numbers that bears his name. Thus, he proved the effectiveness and workability of the proposed system of axioms. Kolmogorov's theory, however, has a weak point: the handling of conditional probability. Everybody regards conditional probability as a highly illustrative concept. Much to the surprise of newcomers to probability theory, this is by far from being the case. As I have already pointed out, the purpose of introducing conditional probability was to be able to tell the probability of a intersections, and conditional probability is the concept whereby "reality" can be injected into the model. At this point, however, a series of technical difficulties arises. For example, in the case of fulfilment of the condition $X=x$, when can the random variable $X$ be substituted with the value $x$ ? The problem stems from the fact that we cannot say what the conditional probability is if the probability of the condition is zero. Generally, zero-probability sets have an overly prominent role in the theory. For example, in the stochastic analysis, what is to be treated as zero probability must be established right at the 
beginning of the investigation. If we identify zero-probability events as impossible events, then we need to say right at the beginning of the investigation which events are possible, and which are not. These are sources of considerable difficulty from both a philosophical and from a mathematical perspective, but unfortunately this is the nature of the system; so far nobody has been able to propose anything better or cleverer.

Weierstrass's example was something of a thorn in the side for science. ${ }^{5}$ The big turning point came with the Wiener process, when it transpired that thermal motion - and, based on Bachelier's research, which attracted little attention at the time, stock market prices - are not differentiable. In other words, the past can tell us nothing about the future. It is perhaps worth noting that Louis Bachelier defended his treatise in 1900 without generating much interest, and at around the same time that Einstein offered the explanation for Brownian motion in his theory of relativity in 1905, thus providing decisive proof of the existence of atoms.

The $18^{\text {th }}$ and $19^{\text {th }}$ centuries tried to understand the world based on the eternal rules of planetary movements and the determinism of differential equations. Even Marx thought that social questions could be understood and channelled in the right direction based on the rules of the material world. What a mistake! The early $2 \mathrm{O}^{\text {th }}$ century built its picture of the world on randomness. The Wiener process is not just a mathematical bravado, but a world view. What can we state with certainty? Maximum statistical parameters, Not even those, in fact. Coincidence and unpredictability rule the world. To be honest, we could lose our savings in any given minute. The best thing even the wisest can say is never put all your eggs in one basket. The victims of foreign-currency loans or brokerage scandals could tell many long stories about this. When developing secondary-school curriculum, it is seriously suggested financial literacy should be taught to the detriment of maths and physics. Naturally, I do not say that this is wrong. All I can say is yes, unfortunately, we need to prepare students for the real dangers. They must be made aware that at any time, a turn of events could result in the loss of all their savings. And this is more important than understanding why the sun rises and how the moon changes.

5 SzőKEFALVI-NAGY, BÉLA (1972): Valós függvények és függvénysorok [Real Functions and Function Series]. Budapest: Tankönyvkiadó, 15. The oft-quoted sentence by Charles Hermite that sums up contemporary reactions is as follows: "I turn with terror and horror from this lamentable scourge of continuous functions with no derivatives." It should be emphasised that the cause of this impassioned reaction was not mathematical in nature; rather, it was triggered by the way the relationship between intuition and mathematics was cast in a dramatically new light. 


\section{REFERENCES}

Feyman, R. P. -Leighton, R.B. -Sand, M. (1986): Mai fizika 5. [The Feynman Lectures on Physics]. Budapest: Műszaki Könyvkiadó.

Medvegyev, Péter (2014): Pénzügyi matematika [Financial Mathematics]. Budapest: Typotex.

SzÁz, János: Valószínűség, esély, relatív súlyok. Opciók és reálopciók [Probability, Change, Relative Weights. Options and Real Options]. Hitelintézeti Szemle 10(4), 336-348.

SzőKefalvi-NAGY, BÉLA (1972): Valós függvények és függvénysorok [Real Functions and Function Series]. Budapest: Tankönyvkiadó. 